\title{
Efficacy of Duloxetine on the Duration of Spinal Anesthesia and Acute Post-Operative Pain after Hip Surgery Prospective Randomized Controlled Study
}

\author{
MOHAMED S. EL-BEHAIRY, M.Sc.; SALAMA I. EL-HAWARY, M.D.; NABIL A. EL-SHEIKH, M.D. and \\ SAMEH M. SADEK, M.D.
}

The Department of Anesthesiology and Surgical Intensive Care, Faculty of Medicine, Tanta University

\begin{abstract}
Background: Prevention and treatment of post-operative pain continue to be a major challenge in post-operative care. Preemptive analgesia has been shown to be effective in reducing the severity of post-operative pain. Serotonin and norepinephrine are involved in the modulation of endogenous analgesic mechanisms, Duloxetine is a selective SerotoninNorepinephrine Reuptake Inhibitor (SNRI) mainly used in the treatment of depression, anxiety and chronic pain. The analgesic effect of duloxetine is believed to result from increased activity of serotonin (5-HT) and Norepinephrine (NE) within the CNS.
\end{abstract}

Aim of Study: The aim of this study was to evaluate the efficacy of pre-operative duloxetine on the duration of spinal anesthesia, severity of post-operative pain, and total analgesic consumption.

Methods and Material: Sixty patients aged 18-60 years, ASA I-II, scheduled for elective hip surgery were randomized into two equal groups: Duloxetine group (Group D): 30 patients received duloxetine $60 \mathrm{mg}$ on two divided doses $30 \mathrm{mg}$ every $12 \mathrm{~h}$ for three days before the operation, $2 \mathrm{~h}$ pre-operative and $12 \mathrm{~h}$ after the surgery. Control group (Group C): 30 patients received placebo capsules by the same way as duloxetine group.

Measurements: Demographic data (age, Body Mass Index (BMI), sex), Hemodynamic (HR, MAP), duration of surgery, duration of spinal anesthesia, post-operative pain was assessed by the Visual Analog Scale (VAS) at 0, 2, 6, 12, 24 and 48h after the surgery, the time at which rescue analgesia was given and total analgesic consumption in $48 \mathrm{~h}$ was recorded

Results: There was no significant difference between both groups as regards to demographic data, hemodynamics (HR \& MAP), duration of surgery and duration of spinal anesthesia. VAS score was significantly lower in in Group D than Group C. Time till administration of first rescue analgesia was significantly prolonger in Group D than Group C.

Conclusions: We conclude from this study that preoperative administration of oral duloxetine $60 \mathrm{mg}$ daily divided into two doses $30 \mathrm{mg}$ every $12 \mathrm{hr}$ for 3 days significantly

Correspondence to: Dr. Mohamed Saed El-Behairy, E-Mail: mohamedelbehairy@med.tanta.edu.eg decreases post-operative pain and total analgesic consumption and improve patient psychology with a significant reduction in associated side effects but has no effect on the duration of spinal anesthesia.

Key Words: Duloxetine - Post-operative pain-Spinal anesthesia - Hip surgery.

Key Message: Pre-operative duloxetine decreases postoperative pain and improve patient satisfaction.

\section{Introduction}

PREVENTION and treatment of post-operative pain continues to be a major challenge in postoperative care and plays an important role in the early mobilization and well-being of the surgical patient [1]

Tissue trauma resulting from surgery can sensitize peripheral nociceptors leading to central neuronal sensitization [2]. Preemptive analgesia has been shown to be effective in reducing the incidence of some types of neuropathic pain [3] Serotonin and norepinephrine are involved in the modulation of endogenous analgesic mechanisms via descending inhibitory pain pathways in the brain and spinal cord so an increase in serotonin and norepinephrine increase inhibition of nociceptive input and improve pain relief.

Duloxetine is a selective SerotoninNorepinephrine Reuptake Inhibitor (SNRI) mainly used in the treatment of depression and anxiety. It has also been shown to be effective in the treatment of chronic as well as neuropathic pain $[4,5]$. The analgesic effect of duloxetine is believed to result from increased activity of serotonin (5-HT) and Norepinephrine (NE) within the CNS presumably either by enhancing descending pain inhibitory pathways in the brain and spinal cord. In addition 
to its SNRI effects, duloxetine also blocks voltagegated sodium channels [6]

\section{Aim and objectives:}

The aim of this study was to evaluate the efficacy of pre-operative duloxetine on the duration of spinal anesthesia, severity of post-operative pain, and total analgesic consumption.

\section{Material and Methods}

After obtaining the Research Ethics Committee approval (approval code: 31569105/17) and informed written consent was taken from the patients, a prospective randomized double-blind study was carried out in Tanta University Hospitals in Orthopedic Surgery Department from June 2017 to June 2018, on sixty patients of ASA 1-II, aged between 18 and 60 years scheduled to undergo hip surgery were enrolled into the present study. Patient refusal, patients with known hypersensitivity to duloxetine, psychiatric patients especially in combination with MAOIs, uncontrolled narrow-angle glaucoma, history of chronic pain, and regular medication with SNRI or analgesic (excluding acetaminophen and non-steroidal anti-inflammatory drugs).

Patients were randomized into two equal groups by using sealed opaque envelop (30 patients in each group) Group D: Duloxetine group: 30 patients received duloxetine $60 \mathrm{mg}$ on two divided doses $30 \mathrm{mg}$ every $12 \mathrm{~h}$ for three days before the operation, $2 \mathrm{~h}$ pre-operative and $12 \mathrm{~h}$ after the surgery Group C: Control group: 30 patients received placebo capsules by the same way as duloxetine group Fig. (1). The measurements were taken by another anesthetist who has no subsequent involvement in the study.

Pre-operative assessment was done by: History taking, clinical examination, laboratory investigations including: $\mathrm{CBC}$, bleeding time and clotting time liver function tests and kidney function tests. Patients fasted according to ASA guidelines. In the holding area, after securing 20-gauge Intravenous (IV) cannula, all the patients were preloaded with Ringer's lactate solution $(10 \mathrm{ml} / \mathrm{kg})$ over 30 minutes.

On the arrival to O.R., the patients were attached to the monitor displaying the following: (ECG, pulse oximetry and NIBP). After the lumbar region was prepared and draped in a sterile fashion, topical $1 \%$ lidocaine was given for skin analgesia. The spinal block was achieved at the L3-4 or L4-5 interspace using a spinal introducer and a $27-\mathrm{G}$ Pencan spinal needle (B. Braun Medical Inc., Bethlehem, PA) and using $3 \mathrm{ml}$ of $0.5 \%$ hyperbaric bupivacaine with $25 \mu \mathrm{g}$ fentanyl. The correct placement of the needle was confirmed by aspiration of clear cerebral spinal fluid before and after the injection. After confirmation of an appropriate dermatomal level of blockage, the surgeon was allowed to proceed.

Oxygen was delivered by an oxygen mask $(5 \mathrm{~L} / \mathrm{min})$ to all patients throughout procedure.

\section{Measurements:}

1-Demographic data (age, Body Mass Index (BMI), sex).

2- Hemodynamic (HR, MAP).

3- Duration of surgery.

4- Duration of spinal anesthesia: The duration was calculated from the time of spinal injection until complete regression from sensory and motor blockade, sensory blockade was assessed by pinprick method and motor blockade was assessed by modified Bromage Scale (0: No motor loss, 1: Inability to flex the hip, 2: Inability to flex the knee joint, 3: Inability to flex the ankle).

5- Post-operatively pain was assessed by the Visual Analog Scale (VAS) (68) at 0, 2, 6, 12, 24 and $48 \mathrm{~h}$ after the surgery. If patients complained of pain (VAS was >_4), they received titrated dose of morphine ( $2 \mathrm{mg}$ bolus at $10 \mathrm{~min}$ interval), and then morphine $20-30 \mathrm{mcg} / \mathrm{kg}$ until the VAS was less than 4 .

6- The time at which rescue analgesia was given and total analgesic consumption in $48 \mathrm{~h}$ was recorded.

Patients were observed for any adverse effects or complications and treated accordingly e.g. bradycardia was treated by atropine $0.01-0.02 \mathrm{mg} / \mathrm{kg}$ hypotension treated with incremental doses of ephedrine $10 \mathrm{mg}$, nausea and vomiting were treated with ondansetron.

The sample size was calculated using Fpi-Info software statistical package created by World Health organization and center for Disease Control and Prevention, Atlanta, Georgia, USA version 2002.

The criteria used for size calculation were as follow:

- $95 \%$ confidence limit.

- $80 \%$ power of the study.

- Expected outcome in treatment group is double times better than control group. In concern to opioid consumption. 
The sample size was based on the previously mentioned criteria was found at $\mathrm{N} \geq 24$ for each study group.

Statistical presentation and analysis were conducted by SPSS V.24. Results were expressed as means \pm Standard Deviation (SD). Student paired $t$-test: For statistical analysis within the same group. Unpaired $t$-test: Used for comparison of parametric data (age, weight, duration of surgery, duration of anesthesia, HR, MAP and RR) between the two studied groups. Modified chi-square test for small numbers: For comparison between two groups as regards qualitative data (sex). Mann Whitney test: Used for comparison of non-parametric data. $p$ value $<0.05$ was considered significant.

\section{Results}

Sixty patients were enrolled in the study from June 2017 to June 2018, patients' baseline characteristics and surgical factors were not different between groups (Table 1).

Duration of spinal anesthesia: There was insignificant difference between both groups when compared to each other as regard to onset and offset of motor block in Group D mean value was $195 \pm 23.3$ while in Group C was $182 \pm 19.6$ ( $p$-value $=0.17$ ), the duration between onset and offset of sensory block in Group D mean value was 225.66 \pm 26.8 , while in Group C was $219 \pm 25.9$ which is insignificant $(p$-value $=0.26)($ Table 1$)$.

Table (1): Demographic data, duration of surgery, duration of anesthesia.

\begin{tabular}{llll}
\hline & Group D & Group C & $p$-value \\
\hline Age (years) & $45.7 \pm 8$ & $43 \pm 8.5$ & 0.62 \\
BMI & $22.2 \pm 1.9$ & $22.5 \pm 2.1$ & 0.72 \\
Sex (M/F) & $16 / 14$ & $17 / 13$ & 0.79 \\
Duration of surgery (min) & $132.07 \pm 13.7$ & $132 \pm 12.3$ & 0.86 \\
Duration of motor block (min) & $195 \pm 23.3$ & $182 \pm 19.6$ & 0.17 \\
Duration of sensory block (min) & $225.66 \pm 26.8$ & $219 \pm 25.9$ & 0.26 \\
\hline
\end{tabular}

*Data presented as mean $\pm \mathrm{SD}$.

The duloxetine group had significantly lower pain scores at all-time points-except at the end of surgery and $2 \mathrm{hr}$ post-operative as the patient still under the effect of the spinal anesthesia both groups were equal Fig. (1).

Total morphine consumption was less in Group D compared with Group C (at 24h, $7.3 \pm 1.23$ Vs. $11.53 \pm 2.55, p<0.001$ and at $48 \mathrm{~h}, 13.56 \pm 2.01 \mathrm{Vs}$. $20.23 \pm 3.12, p<0.001$, respectively) and time to first rescue analgesic was significantly longer in Group D compared with Group C $(4.08 \pm 0.98 \mathrm{~h}$ Vs. $2.81 \pm 0.61 \mathrm{~h}, p<0.001$, respectively) (Table 2 ).

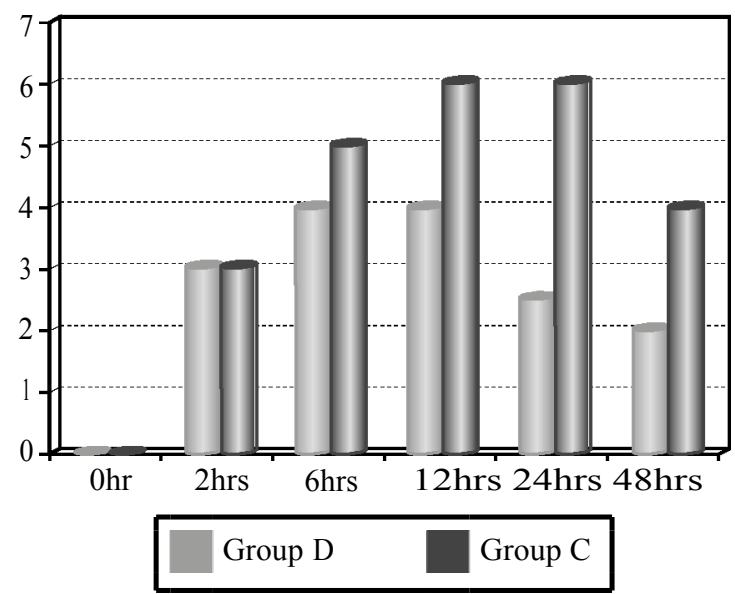

Fig. (1): Comparison between Visual Analogue Score (VAS) changes in both groups.

Table (2): Comparison between first rescue analgesia and total morphine consumption in both groups.

\begin{tabular}{lllllll}
\hline \multirow{2}{*}{ No. } & \multicolumn{2}{c}{ 1st time } & \multicolumn{2}{c}{ Total M 24h } & \multicolumn{2}{c}{ Total M 48h } \\
\cline { 2 - 6 } & \multicolumn{2}{c}{ Group D Group C Group D Group C Group D Group C } \\
\hline Range & $4-5.5 \mathrm{hr}$ & $2-4 \mathrm{hr}$ & $5-10 \mathrm{mg}$ & $8-16 \mathrm{mg}$ & $9-18 \mathrm{mg}$ & $15-26 \mathrm{mg}$ \\
Mean & 4.08 & 2.81 & 7.3 & 11.53 & 13.56 & 20.23 \\
SD & 0.98 & 0.61 & 1.23 & 2.55 & 2.01 & 3.12 \\
$p$-value & $<0.001 *$ & & $<0.001 *$ & \multicolumn{3}{c}{$<0.001 *$} \\
\hline
\end{tabular}

The incidence of side effects was insignificant when compare both groups (Table 3 ).

Table (3): Comparison between side effects in both groups.

\begin{tabular}{lccc}
\hline & Group D & Group C & $p$-value \\
\hline Nausea & 3 & 4 & 0.7 \\
Vomiting & 1 & 1 & 1 \\
Dizziness & 1 & 0 & 0.31 \\
Rash & 0 & 0 & 0 \\
Headache & 1 & 1 & 1 \\
Somnolence & 0 & 0 & 0 \\
\hline
\end{tabular}
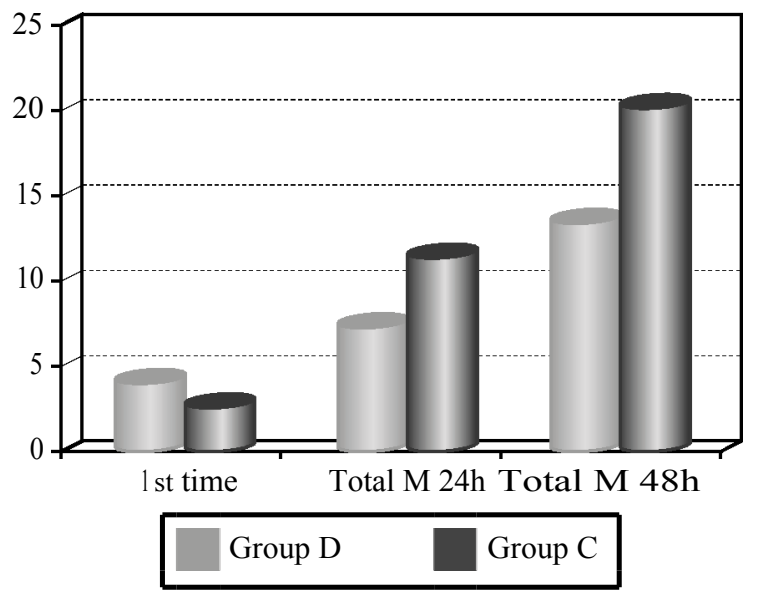

Fig. (2): Comparison between first rescue analgesia and total morphine consumption in both groups. 


\section{Discussion}

A number of post-operative dysfunctions are related directly to post-operative pain. The most important of these are pulmonary, circulatory, gastrointestinal and urinary dysfunction, impairment of muscle metabolism and function, thromboembolic processes and undesirable psychological and emotional reactions that can be transient or prolonged. Thus, it is possible for acute severe unrelieved pain to results in significant morbidity and even mortality [7].

Opioids are considered the drug of choice for management of post-operative pain but it is difficult to induce an optimum analgesia without significant side effects [8], so adjuvants had been used to decrease opioids dose and associated side effects like NSAIDS, Gabapentin, Pregabalin, Ketamine and recently antidepressants as duloxetine are also used as adjuvants, the analgesic effect of antidepressants is typically seen after 7 to 14 days, therefore it's commonly used for chronic pain [9] Recently few studies have been done to evaluate administration of pre-operative duloxetine for acute post-operative pain management [10].

Duloxetine is a selective SNRI that is prescribed for the treatment of depression and anxiety disorders [11]. It is also efficacious in treating pain in diabetic neuropathy and fibromyalgia [12]. The mechanism of its analgesic action could be explained by a combined central and peripheral pain modulating role [13] through the effect of serotonin and norepinephrine on descending inhibitory pain pathways in the brain and spinal cord [14] and activation of some cerebral prefrontal areas [6] Also it has an antinociceptive effect through $\mathrm{Na}+$ channel blocks [5] with antihyperalgesic effects through the inhibition of the neuronal cell firing resulting from peripheral injury. Therefore, duloxetine has a great role in the management of neuropathic pain and reducing post-operative pain. In addition, it may improve the depression and anxiety that are common during the perioperative period.

\section{The regimen of duloxetine administration:}

\section{1- The dose was based on:}

- Previous studies conducted to evaluate the efficacy of pre-operative duloxetine on acute postoperative pain they give duloxetine $60 \mathrm{mg}$ single daily dose for different periods.

- The least effective dose of duloxetine for treatment of chronic neuropathic pain is $60 \mathrm{mg}$ daily.

In contrast to previous studies, we demonstrated that dividing the dose of $(60 \mathrm{mg})$ duloxetine into two doses of duloxetine $30 \mathrm{mg}$ every $12 \mathrm{hr}$ might achieve the targeted pain control and also reduce associated side effects, especially with prolonged use.

\section{2- The duration of drug administration:}

There was great conflict about when we should start the drug pre-operative? This because few studies were done to evaluate duloxetine for acute post-operative pain with different regimens and different results e.g.

Hoi et al., Castro Alves et al., Bedin et, and Kassim DY et al., gave the first dose was $2 \mathrm{hr}$ preoperative depending that the peak level in the blood achieved within $6 \mathrm{hr}$.

Nasr gave the first dose of duloxetine 60mg 2 days before surgery he chose 2 days because this was the time that the patient visited the anesthesia clinic for pre-operative assessment.

Saoud A et al., gave the first dose of duloxetine $60 \mathrm{mg}$ two weeks pre-operative.

The analgesic effect of antidepressants is typically seen after 7 to 14 days; therefore it's commonly used for chronic pain [9]

We chose to start duloxetine 3 days before the operation as according to duloxetine manufacturer's steady level in the blood is achieved after 3 days so avoiding changes in blood concentration of duloxetine leading to better analgesic effect and also avoid side effects associated with prolonged duration of drug administration.

In the present study, we compared the changes in heart rate, mean arterial blood pressure, duration of spinal anesthesia, the time for the first rescue analgesia, total analgesic requirement, postoperative pain assessed by VAS, the level of sedation assessed by modified Ramsey scale between both groups and incidence of side effects.

\section{As regard to hemodynamics:}

There was a slight decrease in mean blood pressure and heart rate in duloxetine group at the start of operation in comparison to placebo group without statistical significance this may be explained be anxiety relieving effect of duloxetine and post-operatively due analgesic effect of duloxetine. In agreement with Kassim DY et al., who found a significant decrease in MAP and heart rate in duloxetine group in comparison to placebo group.

The other previous studies showed no significant difference between both groups. 


\section{As regard to duration of spinal anesthesia:}

We supposed that duloxetine may increase the duration of spinal anesthesia (complete regression of sensory and motor block) this due the drug action on the descending tract and $\mathrm{Na}+$ channel. But we found that there wasn't a statistically significant difference between spinal duration in both groups. So the delayed onset of pain sensation and the delayed rescue analgesia requirement is due to the central effect of duloxetine on pain pathway.

\section{As regard to post-operative pain:}

There was a statistically significant decrease in VAS scores of pain at all-time points-between Group D and Group C $(p<0.001)$ except at the end of surgery and $2 \mathrm{hr}$ post-operative as the patient still under the effect of the spinal anesthesia both groups were equal.

In agreement with our study, Nasr, Castro Alves et al., and Bedin et al., they showed a significant decrease in VAS scores of pain in duloxetine in compare to control group.

In contrast to our results regarding acute pain, Hoi et al., found that pain scores were slightly higher in the first few hours after surgery in the duloxetine group compared with the placebo group; this difference may be related to the time of administration of duloxetine. In Hoi study, the first dose was given just $2 \mathrm{~h}$ before surgery.

In Saoud A et al., study there was not statically significant between two groups he explained this result by decreasing the pain level in the control group with higher opioids consumption than duloxetine group.

\section{As regard to analgesic consumption:}

Total morphine consumption was significantly less in Group D compared with Group C $(p<0.001)$ and the time of the first rescue analgesic was longer; this was consistent with all previous studies however we found more spare in total morphine consumption with the prolonged use of duloxetine in comparison to single pre-operative dose.

\section{As regard to side effect:}

The most common adverse effects of duloxetine, which may lead to discontinuation of the drug, are nausea, vomiting, dizziness, headache, pruritus, and somnolence.

\section{In concern with nausea:}

In Group D, three patients complained of nausea and were treated successfully with ondansetron without new onset symptoms post-operative this was comparable to Group $\mathrm{C}$ where four patients complained of nausea two of them after the induction of spinal anesthesia and two complained of nausea post-operatively due to higher doses of morphine.

Our results are comparable with Nasr showed that the incidence of adverse effects was similar between Group D and Group C showed that the number of patients that experienced nausea was 3 patients from 25 patients in Group P while in Group D was 4.

Also, in agreement with our results, Attia et al., showed that the number of patients that experienced nausea was 13 patients from 30 patients in Group P while in Group D were 7 with a significant difference between both groups, he explained this by higher doses of morphine in control group.

\section{In concern with dizziness and somnolence:}

In Group D only one patient from 30 patients complained of dizziness in comparison to previous studies Nasr showed that 4 patients experienced dizziness and 4 patients complained somnolence. Attia et al., showed that number of patients that 4 patients experienced dizziness and 2 patients complained somnolence. These results could be explained be small divided doses we used.

Hoi et al, Castro Alves et al., and Bedin et al., did not detect any side effects of the drug explaining that patients received only 2 dosages of oral duloxetine.

We did not detect any other side effects associated with the perioperative administration of duloxetine in the current study like somnolence and dry mouth. These results may be explained by the small divided doses we used.

\section{Conclusions:}

We conclude from this study that pre-operative administration of oral duloxetine $60 \mathrm{mg}$ daily divided into two doses $30 \mathrm{mg}$ every $12 \mathrm{hr}$ for 3 days significantly decreases post-operative pain and total analgesic consumption and improve patient psychology with a significant reduction in associated side effects but has no effect on the duration of spinal anesthesia.

\section{Conflicts of interest:}

No conflicts of interest declared.

\section{Authors' contributions:}

All authors had equal role in design, work, statistical analysis and manuscript writing. 


\section{References}

1- WHITE P.F.: The changing role of non-opioid analgesic techniques in the management of post-operative pain. Anesthesia \& Analgesia, 101 (5S): S5-S22, 2005.

2- KANDASAMY R. and PRICE T.J.: The pharmacology of nociceptor priming. Pain Control: Springer, p. 15-37, 2015.

3- VADIVELU N., MITRA S. and NARAYAN D.: Recent advances in post-operative pain management. The Yale Journal of Biology and Medicine, 83 (1): 11, 2010.

4- ARNOLD L.M., ROSEN A., PRITCHETT Y.L., D'SOUZA D.N., GOLDSTEIN D.J., IYENGAR S., et al.: A randomized, double-blind, placebo-controlled trial of duloxetine in the treatment of women with fibromyalgia with or without major depressive disorder. Pain, 119 (1): 515,2005 .

5- WANG S.Y., CALDERON J. and WANG G.K.: Block of neuronal $\mathrm{Na}+$ channels by antidepressant duloxetine in a state-dependent manner. Anesthesiology: The Journal of the American Society of Anesthesiologists, 113 (3): 655-65, 2010.

6- JONES C.K., PETERS S.C. and SHANNON H.E.: Efficacy of duloxetine, a potent and balanced serotonergic and noradrenergic reuptake inhibitor, in inflammatory and acute pain models in rodents. Journal of Pharmacology and Experimental Therapeutics, 312 (2): 726-32, 2005.

7- WARLTIER D.C., PAGEL P.S. and KERSTEN J.R.: Approaches to the prevention of perioperative myocardial ischemia. Anesthesiology: The Journal of the American Society of Anesthesiologists, 92 (1): 253, 2000.

8- WHEELER M., ODERDA G.M., ASHBURN M.A. and LIPMAN A.G.: Adverse events associated with postoperative opioid analgesia: A systematic review. The Journal of Pain, 3 (3): 159-80, 2002.

9- RECLA J.M.: New and emerging therapeutic agents for the treatment of fibromyalgia: An update. Journal of pain research, 3: 89, 2010.

10- HO K.Y., TAY W., YEO M.C., LIU H., YEO S.J., CHIA S.L., et al.: Duloxetine reduces morphine requirements after knee replacement surgery. British Journal of Anaesthesia, 105 (3): 371-6, 2010.

11-HAPPICH M., SCHNEIDER E., BOESS F.G., WILHELM S., SCHACHT A., BIRKLEIN F., et al.: Effectiveness of duloxetine compared with pregabalin and gabapentin in diabetic peripheral neuropathic pain: Results from a German observational study. The Clinical Journal of Pain, 30 (10): 875-85, 2014

12- LUNN M., HUGHES R.A. and WIFFEN P.J.: Duloxetine for treating painful neuropathy, chronic pain or fibromyalgia. The Cochrane Library, 2014.

13- ONUŢU A.H.: Duloxetine, an antidepressant with analgesic properties-a preliminary analysis. Romanian Journal of Anaesthesia and Intensive Care, 22 (2): 123, 2015.

14- WOOLF C.J.: Central sensitization: Implications for the diagnosis and treatment of pain. Pain, 152 (3): S2-S15, 2011.

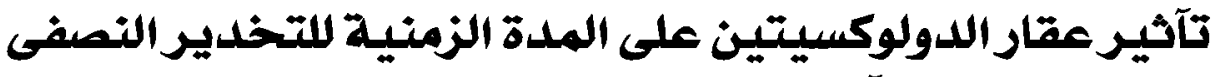

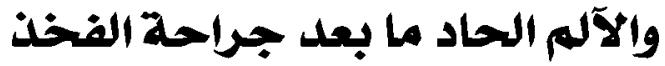

\author{
إن علاج آلم ما بعد الجراحة له دود مهم فى سرعة شفاء المريض وسعرعة الحركة بعد الجراحة. \\ الدولوكستين هو عقار مثبط إتثقائى يمنع إمتصاص السيروتونين والنورادرينالين يستخدم آساساً فى علاج الإكتئاب والقلق . وقد ثبتت فعاليته

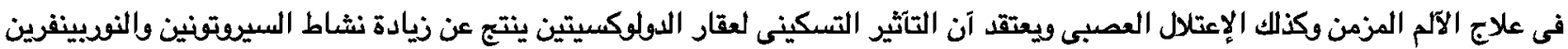

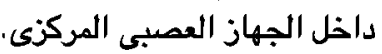 \\ الهدف من هذه الدراسة: هو تقييم فعالية عقار الدولوكسيتين على مدة التخدير النصفى، وشدة الآلم بعد العملية الجراحية، والإستهلاك \\ الكلى المسكنات.

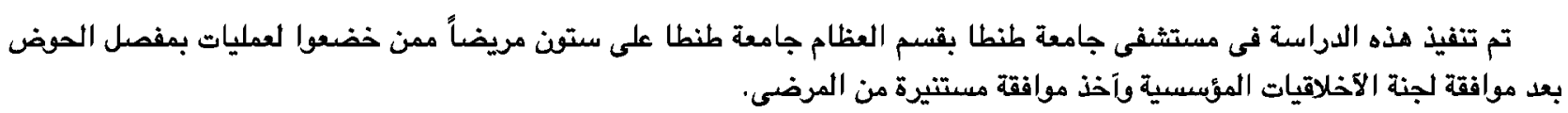 \\ النتائج: آظهرت النتائج آنه لا يوجد إختلاف بين المجموعتين فيما يتعلق بالسن والجنس والوزن ومده العملية ووقت التخدير النصفى وكذلك الكيك

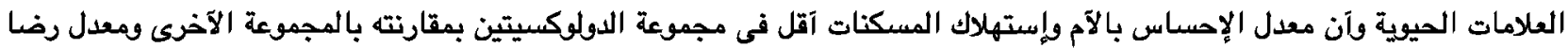 \\ المرضى آكثر من المجموعة الآخرى. \\ الإستتاجات: من خلال الدراسة وجد آن عقار الدولوكسيتين عن طريق القم له لود فعال فى تسكين آلم ما بعد الجراحة وتقليل الإحتياجات

